\title{
Comparison of the simulated upper-ocean vertical structure using 1-dimensional mixed-layer models
}

\author{
Sonaljit Mukherjee ${ }^{1}$ and Amit Tandon ${ }^{1}$ \\ ${ }^{1}$ Department of Mechanical Engineering, University of Massachusetts Dartmouth, 285 Old Westport Rd, North Dartmouth, \\ MA 02747
}

Correspondence to: Sonaljit Mukherjee (smukherjee@umassd.edu)

\begin{abstract}
Atmospheric fluxes influence the momentum and scalar properties in the upper-ocean. Buoyancy fluxes result in a diurnal variability in the sea-surface temperature (SST), whereas the wind stress forms near-inertial currents in the mixed layer (ML). In this study, we investigate the contrasts between the simulated SST and the vertical structure of the temperature and shear by three different mixing models: the PWP bulk mixed-layer model, the KPP non-local boundary layer model and the

$5 k-\epsilon$ local mixing model. We choose two upper-ocean datasets for our studies, namely the SWAPP (1990) and the MLML (1991). The SWAPP dataset shows the presence of strong near-inertial shear below the ML and negligible near-inertial shear within the ML. The MLML dataset shows a negligible rise in the SST during the first 22 day mixing phase, which is followed by a steep rise by $6^{\circ} \mathrm{C}$ during the subsequent 75 day restratification phase.

Comparison with the SWAPP dataset shows that the KPP and $k-\epsilon$ models form strong shear near the surface due to weak eddy viscosities, thus producing a thin shear layer over the entire range of frequencies in the wind stress. At the ML base, the models form an inertial and a diurnal maximum. The inertial maximum extends over a substantial range of depths, and is continuous for the $k-\epsilon$ model but discontinuous for the KPP and PWP models.

Comparison with the MLML dataset reveals that the KPP yields the largest SST amplitude over a 24-hour diurnal cycle, and is followed by the $k-\epsilon$ and PWP. However, the net warming of SST at the end of the diurnal cycle is stronger for the PWP compared to $k-\epsilon$ and KPP. The PWP also forms stronger temperature gradients at the ML base compared to $k-\epsilon$ and KPP. Over multiple diurnal cycles, the shallowing and deepening of the mixed layer results in multiple sharp temperature gradients in PWP, thus forming a serrated vertical profile that remains unaffected during the restratification phase of the MLML dataset.
\end{abstract}

\section{Introduction}

The upper ocean is subject to turbulent mixing by local and advective processes. Among the local processes, wind stress and atmospheric cooling enhance the turbulence and deepen the ML, whereas atmospheric warming weakens the turbulence and shallows the ML. Due to computational limitations in resolving turbulent flows at the small scales, turbulent mixing is represented in 3-dimensional models by various 1-dimensional (1D) mixing parameterizations. In this paper, we explore the impact of three commonly used mixing parameterizations on the vertical structure of the momentum and scalar properties in the upper-ocean. 
Ocean Sci. Discuss., doi:10.5194/os-2016-45, 2016

Manuscript under review for journal Ocean Sci.

The simplest approach to address the vertical mixing is the Bulk mixed-layer parameterization which considers the ML to be vertically uniform in terms of the temperature, salinity and velocities. The Price-Weller-Winkel model (PWP) is a widely used 1D model that implements the Bulk mixed-layer parameterization (Price, 1979). At a higher level of dynamical complexity, the KPP (Large et al., 1994) and second order closure models (Rodi, 1987; Mellor and Yamada, 1982; Canuto et al., 2001b) estimate vertically varying eddy viscosity profiles within the ML. The KPP is a non-local mixing model since it estimates eddy viscosities based only on the surface boundary layer depth and the surface fluxes (Large et al., 1994). Local mixing parameterizations estimate the turbulent mixing and eddy viscosities based on both surface fluxes and the local shear and stratification in the water column. Second-order closure models $k-\epsilon$ (Rodi, 1987; Canuto et al., 2001b; Gibson and Launder, 1976) and $k-k L$ (Mellor and Yamada, 1982) belong to the category of local mixing parameterizations.

The performance of different 1D mixed-layer models have been compared with various upper ocean datasets, e.g. OWS PAPA, OWS November, MILE, LOTUS and FlexLM (Kantha and Clayson, 1994). These comparative studies have examined the evolution of various properties like the MLD, SST and the vertical structure of the scalar and momentum properties. The 1D mixed-layer models that implement different mixing parameterizations have been noted to perform reasonably well when compared with the aforementioned datasets. For example, the bulk mixed-layer model PWP, non-local model KPP and turbulence closure model $k-k L$ (Mellor and Yamada, 1982) show a similar evolution of the MLD when forced with the fluxes obtained from these datasets (Kantha and Clayson, 1994). In idealized simulations with constant surface cooling, the KPP has been noted to deepen the ML further than the turbulence closure models (Large et al., 1994; Burchard and Bolding, 2001).

The upper ocean exhibits a diurnal variability in the SST as a response to the surface heat fluxes. This diurnal SST variability depends not only on the magnitude of the heat fluxes but also the wind stress. Strong winds reduce the diurnal amplitude of SST due to enhanced turbulent mixing and entrainment, whereas relatively weaker winds make the ML more prone to shallowing and restratification, thereby increasing the diurnal SST amplitude (Brainerd and Gregg, 1995; Kawai and Wada, 2007). Such diurnal variability needs to be accurately reproduced in numerical models in order to reproduce realistic SST variations over intra-seasonal time scales (Kawai and Wada, 2007). The diurnal variability of the SST due to the incoming heat fluxes has been demonstrated by the mixing models $k-\epsilon, k-k L$ and KPP despite insufficient representation of the vertical mixing (Kantha and Clayson, 1994) when compared with upper-ocean datasets. However, the contrast between the diurnal SST variability produced by different mixing parameterizations, and it's underlying causes, needs further exploration. It is also of interest to study how this contrast impacts the simulated SST variability over intra-seasonal time scales.

Wind forcing at the surface generates near-inertial currents in the ML (D'Asaro, 1985; Kato and Phillips, 1969), which decay in the transition layer (Majumder et al., 2015). Upper ocean measurements at the research platform Flip during the Surface Waves Processes Program (SWAPP) (Weller and Plueddemann, 1996) have further shown that the near-inertial component of the vertical shear is quite intense between the ML base and the seasonal thermocline, but negligible within the ML due to strong mixing (Plueddemann and Weller, 1999). Such a vertical structure of the shear below the ML was also demonstrated by the PWP model (Plueddemann and Weller, 1999). However the PWP, being a Bulk mixed-layer model, is expected to remove any vertical shear within the ML since it homogenizes the scalar and momentum properties by assuming infinite mixing. On the other hand, non-local and local mixing parameterizations yield vertical shear within the ML since they form finite eddy 
Ocean Sci. Discuss., doi:10.5194/os-2016-45, 2016

Manuscript under review for journal Ocean Sci.

Published: 22 July 2016

(c) Author(s) 2016. CC-BY 3.0 License.

(c) $($ P)

viscosities that vary with the depth. It is therefore interesting to explore the vertical structure of the shear generated by the non-local and local mixing parameterizations, and see whether or not the simulated shear within the ML has a near-inertial component.

\subsection{Motivation}

5 Motivated by the above discussion, we aim to explore the following questions in this study:

- What is the impact of different vertical mixing parameterizations on the SST variability over a diurnal cycle, and how does it influence the SST variability over intra-seasonal time scales?

- What is the vertical structure of the simulated shear by local and non-local mixing models, and how do they compare with the Bulk mixed-layer model?

To address the above questions, we conduct simulations using three different mixing models that represent the three aforementioned mixing parameterizations: The Bulk mixed-layer model PWP, the non-local mixing model KPP and the local mixing model $k-\epsilon$. For the $k-\epsilon$ model, we choose the stability function coefficients by Canuto et al. (2001a) since it has produced the most realistic and numerically stable results from idealized simulations on wind entrainment and convective cooling (Umlauf and Burchard, 2005; Burchard and Bolding, 2001), and upper ocean datasets like the OWS PAPA (Burchard and Bolding, 2001). For studying the evolution of the simulated SST we choose the MLML dataset which is characterized by a 22 day mixing phase followed by a 75 day restratification phase during which the SST elevates by $6^{\circ} \mathrm{C}$. For studying the simulated vertical shear in the upper ocean we choose the SWAPP dataset (Weller and Plueddemann, 1996; Plueddemann and Weller, 1999). The characteristic features of the SWAPP dataset include the presence of intense near-inertial shear below the ML and negligible near-inertial shear within the ML, which was also demonstrated by the PWP model results (Stramska and Dickey, 1995).

This paper is structured as follows: Section 2 discusses the Bulk mixed-layer parameterization, the non-local and local mixing parameterizations and the associated models. Section 3 briefly discusses the upper-ocean observations during SWAPP and MLML. Section 4 compares the observations and the simulation results using the three mixing models, including the difference between their performances. Section 5 summarizes the conclusions.

\section{Mixing Parameterizations}

\subsection{Bulk mixed-layer parameterization}

A bulk mixed-layer parameterization treats the upper ocean ML as a single unit and homogenizes the momentum and scalar properties within the ML. For the deepening and shallowing of the ML, this parameterization takes into account only the surface heat and momentum fluxes. Examples of models that work on this parameterization are Kraus-Turner's 1D model 
Ocean Sci. Discuss., doi:10.5194/os-2016-45, 2016

Manuscript under review for journal Ocean Sci.

Published: 22 July 2016

(c) Author(s) 2016. CC-BY 3.0 License.

for the seasonal thermocline (Kraus and Turner, 1967), the analytical model for ML deepening (Pollard et al., 1972) and the Price-Weller-Pinkel (PWP) mixed layer model (Price et al., 1986).

The Price-Weller-Pinkel (PWP) model (Price et al., 1986) is a widely used Bulk mixed-layer model that incorporates two other mixing parameterizations for convective adjustment during unstable stratification, and shear-instability based mixing at the base of the ML. The mixing process in the PWP begins with the convective adjustment where the grid cells with unstable stratification are homogeneously mixed with the adjoining cells. The convective adjustment is followed by the Bulk mixedlayer parameterization where the ML deepens when $R i_{b}$ falls below a threshold value of 0.65 (Price et al., 1986). The Bulk Richardson number $R i_{b}$ is expressed as

$R i_{b}=\frac{\Delta \rho g}{\rho_{0}(\Delta U)^{2}}$,

where $\Delta \rho$ is the difference between the density within the ML when considered as a single unit, and the density below the ML (Price et al., 1986). Likewise, $\Delta U$ is the corresponding difference between the velocity of the ML, and below the ML. The variables $\rho_{0}$ and $g$ are the reference density and acceleration due to gravity respectively. The third step involves local shear instability below the ML, where mixing due to strong shear is parameterized on the basis of a threshold gradient Richardson number $R i_{g}=N^{2} / S^{2}=0.25\left(S^{2}\right.$ is the shear squared below the ML).

Albeit simpler when compared to turbulence closure models, simulations using the model PWP have shown realistic results when compared to different upper-ocean datasets like sea-surface temperature (SST), MLD, 1D heat budgets (Price et al., 1986; Stramska and Dickey, 1995; Kantha and Clayson, 1994), the Ekman layer depth (Plueddemann and Weller, 1999) and the near-inertial shear below the ML (Plueddemann and Weller, 1999).

\subsection{Non-local mixing parameterization}

Here, the profiles of eddy viscosity and eddy diffusivity within the ML are calculated based on the surface fluxes and the depth of the ML, and not on the local properties within the ML. An example of a widely used model of this kind is the K-profile parameterization (KPP) (Large et al., 1994). The KPP quantifies the depth of the surface boundary layer (SBL) based on a threshold Bulk Richardson number, and prescribes the eddy viscosity profile within the SBL based on a turbulent velocity scale, the surface fluxes, and an ad-hoc polynomial shape function. Since the SBL is deeper than the ML, the KPP yields eddy viscosities in the thermocline as well. The eddy viscosity in KPP is given as

$\nu_{m}=h w_{t}(\sigma) H(\sigma)$,

where $\sigma=z / h$ is the ratio of the depth where $\nu_{m}$ is prescribed, to the surface boundary layer depth $h$. The variable $w_{t}$ is the turbulent velocity scale, and $\mathrm{H}$ is a polynomial shape function of $\sigma$. The velocity scale is given as

$w_{t}=\frac{\kappa u_{*}}{\Phi(\lambda)}$

where $\Phi$ is a non-dimensional flux profile of the stability parameter $\lambda$ (Troen and Mahrt, 1986; Large et al., 1994; Durski et al., 2004), which varies with the surface heat flux. The cubic polynomial function $H$ (eq 2 ) is expressed as

$H(\sigma)=\sigma\left[1+\sigma\left((\sigma-2)+(3-2 \sigma) H(1)+(\sigma-1) H^{\prime}(1)\right)\right]$ 
Ocean Sci. Discuss., doi:10.5194/os-2016-45, 2016

Manuscript under review for journal Ocean Sci.

Published: 22 July 2016

(c) Author(s) 2016. CC-BY 3.0 License.

Apart from mixing in the SBL, the KPP also performs interior mixing below the boundary layer by shear-driven turbulence, internal waves and double diffusion. This model parameterizes the eddy viscosity associated with shear-driven mixing as follows:

$\nu_{i}= \begin{cases}\nu_{0}, & R i_{g}<0 \\ \nu_{0}\left[1-\left(R i_{g} / R i_{0}\right)^{2}\right]^{3}, & 0<R i_{g}<R i_{0} \\ 0, & R i_{g}>R i_{0}\end{cases}$

5 where $\nu_{0}=5 \times 10^{-3} \mathrm{~m}^{2} \mathrm{~s}^{-1}, R i_{0}=0.7$ and $R i_{g}$ is the Richardson number at the base of the SBL.

\subsection{Local mixing parameterization}

This class of mixing parameterization estimates the vertical eddy viscosity at a given depth based on the local stratification and shear at that depth as well as the surface fluxes. This characteristic feature estimates the eddy viscosities and diffusivities based on the local properties like shear and stratification irrespective of the depth of the ML.

Second order closure models like the $k-\epsilon$ (Rodi, 1987) and the $k-k L$ (Mellor and Yamada, 1982) achieve local mixing by parameterizing the turbulent kinetic energy $k$, it's dissipation rate $\epsilon$, and the turbulent length scale $L$. The $k-\epsilon$ model uses the following two transport equations for the evolution of $k$ and $\epsilon$. They are

$\frac{D}{D t} k=\underbrace{\frac{\partial}{\partial z}\left(\frac{\nu_{m}}{\sigma_{k}} \frac{\partial}{\partial z} k\right)}_{\text {Downgradient transfer } \mathrm{D}_{\mathrm{k}}}+\underbrace{\nu_{m} S^{2}}_{\text {Shear production PBuoyancy production B }}-\underbrace{\epsilon}_{\text {Dissipation }}$

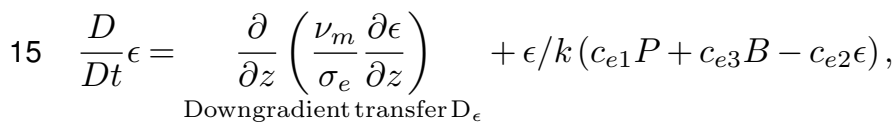

where $\sigma_{k}$ and $\sigma_{e}$ are turbulent Schmidt numbers for $k$ and $\epsilon$ respectively. The variables $S^{2}, N^{2}, \nu_{m}$ and $\nu_{s}$ denote the shear squared, buoyancy frequency, eddy viscosity and eddy diffusivity respectively. The variables $c_{e 1}, c_{e 2}, c_{e 3}$ are empirically determined coefficients (Rodi, 1987). The coefficients $c_{e 1}$ and $c_{e 2}$ are set to 1.44 and 1.92 respectively, whereas $c_{e 3}$ varies between -0.62 and 1 for stable and unstable stratification respectively (Burchard et al., 1999). The eddy viscosity $\nu_{m}$ and eddy diffusivity $\nu_{s}$ are estimated as $\nu_{m}=c_{\mu} k^{2} / \epsilon$ and $\nu_{s}=c_{\mu}^{\prime} k^{2} / \epsilon$ where $c_{\mu}$ and $c_{\mu}^{\prime}$ are empirically derived stability functions for $\nu_{m}$ and $\nu_{s}$ respectively. For our simulations, we use the stability functions defined by Canuto et al. (2001a).

\section{Upper Ocean Datasets}

\subsection{Surface waves processes program (SWAPP)}

The vertical water-column properties were measured using instruments deployed from the booms attached to the research platform FLIP (Weller and Plueddemann, 1996) at the location $35.14^{0} \mathrm{~N}, 126.98^{\circ} \mathrm{W}, 550 \mathrm{~km}$ west of Point Conception, CA. 
Ocean Sci. Discuss., doi:10.5194/os-2016-45, 2016

Manuscript under review for journal Ocean Sci.

Horizontal velocities were measured by an array of Vector Measuring Current Meters (VMCM) at the depths $z_{v m c m}=-2.25$ $\mathrm{m},-4.5 \mathrm{~m},-6.75 \mathrm{~m},-9 \mathrm{~m},-11.25 \mathrm{~m},-15.75 \mathrm{~m},-20.25 \mathrm{~m},-24.75 \mathrm{~m},-33.75 \mathrm{~m},-41 \mathrm{~m},-53.25 \mathrm{~m},-70 \mathrm{~m},-100 \mathrm{~m},-132.25$ m. Temperature and salinity were simultaneously measured using an array of CTDs (Weller and Plueddemann, 1996) evenly spaced at a vertical resolution of $1 \mathrm{~m}$. The sampling time interval was 15 minutes.

To explore the temporal evolution of the upper-ocean vertical structure under the influence of surface winds, Plueddemann and Weller (1999) examined a subset of the observed data from 24th February to 18th March. Since the diurnal variation in the vertical stratification and the MLD contaminates the vertical shear due to wind forcing and surface waves, the velocity structure of the upper ocean obtained from the VMCM measurements was difficult to interpret. Hence, in order to remove this time-varying influence of the stratification, the vertical profiles of the velocities were re-mapped to a different grid where the MLD was constant and equal to the mean value of the time-varying MLD over the 23 day period (Weller and Plueddemann, 1996; Plueddemann and Weller, 1999).

This re-mapping of the vertical grid produced a vertical structure of the shear where majority of the energy associated with the shear was observed to be concentrated within a near-inertial (NI) band below the ML. The vertical structure of the measured shear was consistent with the slab-layer parameterization (Kraus and Turner, 1967) since there was no NI shear within the ML, whereas the rest of the vertical profile of showed the presence of strong NI shear.

The clockwise component of rotary auto-spectra of the vertical shear from simulations using PWP (Price, 1979) mixing model was consistent with the observed spectra from SWAPP, thus agreeing with the slab-layer parameterization. The PWP, being a bulk mixed-layer model (Price, 1979), cannot be expected to form such local variations in the vertical shear at any frequency within the ML. However, non-local and local mixing models have shown the formation of local vertical shear within the ML in 1D simulations of wind-induced entrainment(Burchard, 2002; Burchard and Bolding, 2001; Large et al., 1994). We therefore investigate the vertical structure of the shear formed by the $k-\epsilon$ and KPP mixing parameterizations and explore the frequency distribution of this shear within and below the ML.

\subsection{Marine light-mixed layer experiment (MLML)}

Observations of the upper ocean vertical structure during the spring-to-fall transition were conducted as part of the Marine Light-Mixed Layer Experiment (MLML) at a mooring station located at $59^{\circ} 31.61^{\prime} \mathrm{N}$ and $20^{\circ} 57.85^{\prime} \mathrm{W}, 275$ miles South of Reykjavík, Iceland. The temperature and velocities were measured along an array of bins at the depths given by $z_{m l m l}=(0 \mathrm{~m}$, $10 \mathrm{~m}, 30 \mathrm{~m}, 50 \mathrm{~m}, 70 \mathrm{~m}, 80 \mathrm{~m}, 102 \mathrm{~m}, 118 \mathrm{~m}, 150 \mathrm{~m}, 166 \mathrm{~m}, 182 \mathrm{~m}, 198 \mathrm{~m}, 214 \mathrm{~m}, 230 \mathrm{~m}, 246 \mathrm{~m}, 310 \mathrm{~m}$ ). Analysis of the MLML measurements (Stramska and Dickey, 1995) have shown an initially well-mixed water column for the first 20 days, followed by restratification after the Spring transition (22nd May) (Stramska and Dickey, 1995). The restratification continued till 5th August which marks the Fall transition.

We now briefly summarize the major findings of the MLML experiment during a 4 month period from 30th April to 5th September. During the first 22 day mixing phase (hereafter the M phase) the MLD, defined as a depth where the water was cooler than the SST by $0.01^{\circ} \mathrm{C}$, showed a strong diurnal response ranging from a daytime minimum of $30 \mathrm{~m}$ to a nighttime maximum of $50 \mathrm{~m}$. The Spring transition marked the end of the M phase, and was followed by the restratification phase 
Ocean Sci. Discuss., doi:10.5194/os-2016-45, 2016

Manuscript under review for journal Ocean Sci.

(hereafter R phase) where the ML shallowed to an average depth of $10 \mathrm{~m}$ over a period of 75 days. The observed SST during the $\mathrm{R}$ phase elevated by $6^{\circ} \mathrm{C}$ at the end of the Fall transition (5th August). The simulated MLD and SST evolution using the model PWP forced with the MLML fluxes, were consistent with the observations during the M and R phases (Stramska and Dickey, 1995). This similarity suggests that the upper ocean dynamics during the $M$ and $R$ phases was primarily $1 \mathrm{D}$. Even though shipboard surveys during the mixing phase observed a lateral temperature gradient of $0.5^{\circ} \mathrm{C}$ over $25 \mathrm{~km}$, implying a potential for advective processes (Stramska and Dickey, 1995), the model results revealed that the influence of surface fluxes was dominant compared to the horizontal advection. However, lack of information on the lateral temperature gradients during the $\mathrm{R}$ phase made it difficult to assess the influence of advective processes during that period. Nevertheless, the PWP results agreed reasonably well with the observed SST and MLD evolution in the mixing phase.

\section{Results}

\subsection{Comparison with the SWAPP dataset}

We reproduce the PWP simulation results (Plueddemann and Weller, 1999) by initializing the PWP model with vertical profiles measured on 24th February and forcing it with the measured atmospheric fluxes within the specified period. We further conduct 1D simulations using the non-local KPP model and the local $k-\epsilon$ model with the same initialized profiles and surface fluxes. The grid resolution in our simulations is $1 \mathrm{~m}$ and uniform throughout the depth. The simulations using the PWP, KPP and $k-\epsilon$ models are named as PWP, KPP and CA respectively. The time step for the simulations is 15 minutes. We estimate the MLD in our simulations as a depth where the temperature is $0.01^{\circ} \mathrm{C}$ cooler than the surface temperature.

The vertical resolution of the VMCM bins below $25 \mathrm{~m}$ was $\mathrm{O}(10 \mathrm{~m})$ which is coarser than $\mathrm{O}(1 \mathrm{~m})$ resolution in the simulation results, making it difficult to accurately resolve the observed vertical shear below $25 \mathrm{~m}$ (Figure 2a). The model results show strong vertical shear at the ML base (Figure 2b,c,d). The shear profiles from the simulations CA and KPP show two maxima: one at the surface and the other at the ML base (Figure 2b,c) whereas the PWP shows only one maximum (Figure 2c). The shear maximum at the surface for CA and KPP are caused by the combined influence of the wind stress and weak eddy viscosity at the surface (Figure 4). In contrast, the PWP shows a maximum at the ML base which is a consequence of the bulk mixed-layer parameterization (Price, 1979). Due to this uniform distribution of momentum within the ML, any increment in the vertical shear by the strong wind events is transferred to the base of the ML (Plueddemann and Weller, 1999).

Due to the presence of horizontal advection and surface waves in the measured data, a direct comparison of the modeled and the observed MLD cannot be done. Among the simulations, the KPP forms the deepest ML and the PWP forms the shallowest ML during both heating and cooling phases of each diurnal cycle. This trend is consistent with earlier comparative studies using datasets from the OWS PAPA (Kantha and Clayson, 1994) as well as idealized convection simulations (Umlauf and Burchard, 2005) based on the Willis-Deardorff experiment (Willis and Deardorff, 1974).

We focus on the following dates corresponding to the events characterized by short periods of strong winds: 28th February, 3rd March, 6th March and 9th March. During each of these events, the ML and consequently the shear maximum below the ML base deepens further due to the strong winds in the three simulations (Figure 2). Such deepening is difficult to identify 
Ocean Sci. Discuss., doi:10.5194/os-2016-45, 2016

Manuscript under review for journal Ocean Sci.

in the observed shear due to coarse resolution. Following the strong-wind event, the shear maximum below the ML remains at the same depth for subsequent times until it further deepens due to the next strong-wind event. As the wind stress weakens over the next two days following the last strong-wind event (9th March), the ML shallows (Figure 2e), forming a vertical layer of low shear over a depth-range of $20 \mathrm{~m}$ to $60 \mathrm{~m}$ in PWP, $40 \mathrm{~m}$ to $70 \mathrm{~m}$ in CA and $50 \mathrm{~m}$ to $80 \mathrm{~m}$ in KPP . Despite the coarse vertical resolution of the VMCM measurements, this low-shear layer can be spotted in the observed data as well (Figure 2), spanning a depth range of $40 \mathrm{~m}$ and $60 \mathrm{~m}$ over the specified time period.

In order to compare the frequency distribution of the vertical shear from the model results with the observations, we perform a re-mapping (section 3.1) of the simulated vertical shear over a grid with a constant MLD of $20 \mathrm{~m}$, similar to Weller and Plueddemann (1996); Plueddemann and Weller (1999).

The clockwise component of the rotary auto-spectra of the simulated vertical shear, re-mapped on the grid with a constant MLD, shows the following features. The simulations CA and KPP show a thin shear layer near the surface spanning a wide range of sub-inertial and super-inertial frequencies (Figure 3) where the intensity of the clockwise component lies within a range of 10-0.4-10 $1 \mathrm{~s}^{-2}$. Following Plueddemann and Weller (1999), any magnitude of the auto-spectral component below this specified range is considered negligible. This near-surface shear layer is not present in the observed spectra and the PWP simulations. The formation of this band is a consequence of weak vertical eddy viscosity near the surface, which intensifies the vertical shear over the entire range of frequencies present in the wind stress. In contrast, the PWP results do not show such a thin band near the surface as it is a Bulk mixed-layer model.

Below the $20 \mathrm{~m}$ deep ML, the simulation CA shows a continuous vertical band over a depth ranging from the ML base to the bottom, where the clockwise component of the rotary-spectra $\left(\log _{10} \mathrm{cw}\left[\mathrm{s}^{-2}\right]\right)$ lies within the range of $(-0.4-1)$. In contrast, the inertial bands in the simulations PWP and KPP are discontinuous. The inertial bands from all the simulations show maxima at three different depths: at the base of the ML, at a sub-surface depth of $50 \mathrm{~m}$ and at the seasonal thermocline (90 m). The inertial maximum at the ML base forms due to the influence of the Coriolis rotation which, in the absence of turbulent mixing due to strong stratification, is the only force acting on the velocities at the ML base. The inertial maxima observed at a depth of $50 \mathrm{~m}$ and at the seasonal thermocline are due to the deepening of the mixed layer during the strong-wind events, which form strong shear at deeper depths. In the absence of mixing, this shear persists for subsequent times, and is influenced only by the Coriolis rotation (Plueddemann and Weller, 1999). Compared to the rotary auto-spectra from the simulation results, the inertial maxima in the observed auto-spectra are less intense because the energy associated with the inertial motions was reduced by the horizontal and vertical propagation of internal waves (Weller and Plueddemann, 1996).

The contrast between the stratified shear formed by the local, non-local and Bulk mixed-layer schemes is reflected in the corresponding intensities of the vertical shear below the ML at sub-inertial and super-inertial frequencies. While the local mixing in CA reduces the intensity of the vertical shear below the ML at all frequencies, the corresponding shear in KPP and PWP are stronger since both these simulations do not have a parameterization for vertical mixing below the ML. The inertial maximum in PWP is stronger than that in KPP due to shallower ML and consequently stronger vertical (Figure 2e).

Apart from the inertial maximum, the rotary auto-spectra from the simulated results also show the presence of strong shear at the diurnal frequency of $0.0042 \mathrm{cph}$ which is slightly less than the inertial frequency of $0.0048 \mathrm{cph}$ (Figure 3 ). At the ML 
Ocean Sci. Discuss., doi:10.5194/os-2016-45, 2016

Manuscript under review for journal Ocean Sci.

base, this strong shear forms a secondary maximum in all the simulations. However, within the ML, this maximum is noted only in the simulation CA. The results from PWP and KPP do not show such strong diurnal shear within the ML due to the following reasons: In PWP the Bulk mixed-layer scheme removes any existing shear caused by the wind, whereas in KPP the eddy viscosities are strong enough to mix the vertical shear at all frequencies, which reduces the spectral intensity (log) of the diurnal shear to below the range of $(-0.4-1)$.

\subsection{Comparison with the MLML dataset}

Similar to the model setup for the PWP simulations, (Stramska and Dickey, 1995) the temperature and velocity profiles measured during 30th May at the MLML mooring are interpolated to a uniform grid with a vertical resolution of $1 \mathrm{~m}$. We use the zonal and meridional wind stress and buoyancy fluxes (Figure 5) sampled at every 15 minutes at the mooring (Stramska and Dickey, 1995). The simulations using PWP, KPP and $k-\epsilon$ models are named as PWP, KPP and CA respectively.

During the first 22 day $\mathrm{M}$ phase, all the simulations produce similar temperature profiles with a similar diurnal amplitude (Figure 6). The 22nd day (22nd May, yearday 142) marks the Spring transition when the M phase is followed by the R phase during which there is warming near the surface (Figure 6a) and shallowing of the ML. The observed SST during the R phase reaches a peak of $14^{\circ} \mathrm{C}$ during the Fall transition (5th Aug, yearday 217). The period following the Fall transition shows the influence of mostly advective processes (Stramska and Dickey, 1995), and is therefore not considered in our analysis since all our simulations are 1D. While the three simulations show a similar rise in the temperature near the surface, there is a marked contrast between the maximum temperatures at the end of the fall transition (Figure 6b,c,d, Figure 7). The Simulations CA and KPP yield maximum temperatures $11.7^{\circ} \mathrm{C}$ and $11.5^{\circ} \mathrm{C}$ at the surface (SST) respectively whereas PWP yields an SST of $13.7^{\circ} \mathrm{C}$. The warming during the R phase in the PWP is closest to the observed SST compared to the other simulations.

During the M phase, although the observed SST show strong diurnal variations (Figure 7), the net increment in the SST is negligible. The results from all the models show a similar net increment of SST over the M phase. Following the M phase, the $\mathrm{R}$ phase is characterized by a stronger diurnal variation in the observed SST with a net increment of $6^{\circ} \mathrm{C}$ by the end of the Fall transition (Figure 7). The PWP results show a rise in the SST by $5.2^{\circ} \mathrm{C}$ during the $\mathrm{R}$ phase which is similar to the observed increment but not equal. The results from the simulations CA and $\mathrm{KPP}$ show an SST rise of $3.7^{\circ} \mathrm{C}$ and $3.5^{\circ} \mathrm{C}$ respectively, which are markedly different from the observations and the PWP results in terms of the magnitude. In the following paragraph, we discuss the reason for this difference.

In a Bulk mixed-layer model, a change in the net heat content is evenly distributed over the mixed layer, such that the simulated SST by the model is equal to the temperature everywhere within this layer (Price et al., 1986). In contrast, the $k-\epsilon$ and the KPP form depth-varying eddy diffusivities which variably the mix the temperature fluxes, thereby creating temperature gradients within the mixed layer (Burchard and Bolding, 2001; Kantha and Clayson, 1994; Large et al., 1994). It is thus evident that while the SST in the three simulations depend on the temperature fluxes and the MLD, the local eddy diffusivity in the $k-\epsilon$ and KPP near the surface also has an impact on the temperature gradient near the surface, and subsequently the SST. To understand this difference between the PWP, $k-\epsilon$ and KPP, we examine the diurnal variability of the simulated SST with the heat content during the $\mathrm{M}$ and $\mathrm{R}$ phases. 
Ocean Sci. Discuss., doi:10.5194/os-2016-45, 2016

Manuscript under review for journal Ocean Sci.

The depth-integrated heat content $\left(H_{q}\right)$ is given as

$H_{q}=\int_{z_{b}}^{0} \rho_{0} C_{p}\left(T-T_{0}\right) d z$,

where $\rho_{0}$ is the reference density, $T$ is the temperature at an intermediate depth $z$ within the water column, $T_{0}$ is the temperature at the depth $z$ at the beginning of a diurnal cycle, $z_{b}$ is the total depth, and $C_{p}$ is the specific heat of water. The heat content $H_{q}$ is obtained by integrating the difference between the instantaneous temperature $(T)$ and the temperature at the beginning of a diurnal cycle $\left(T_{0}\right)$ over the depth of the water column (Price et al., 1986).

We compare the diurnal variability of $H_{q}$ with the SST during the $\mathrm{M}$ and R phases separately for the different simulations. This diurnal variability is obtained separately for the $\mathrm{M}$ and $\mathrm{R}$ phases by averaging $H_{q}$ and SST over 22 diurnal cycles from 1 st May to 22nd May for the M phase, and 75 diurnal cycles from 23rd May to 5th August for the R phase (Figure 8a,b). In each phase, the diurnal cycle is divided into three zones: the morning zone $(\mathrm{A} \rightarrow \mathrm{B})$, the afternoon zone $(\mathrm{B} \rightarrow \mathrm{C})$ and the nighttime zone $(\mathrm{C} \rightarrow \mathrm{D})$ (Figure 8a,b). The morning zone is characterized by a steady rise in the heat content of the system due to the combination of the shortwave, heat loss and the radiative fluxes $\left(Q_{n e t}>0\right.$ and $d Q_{n e t} / d t>0$, where $Q_{n e t}$ is the net heat flux). The afternoon zone is characterized by a heat flux that remains positive but decreases with time $\left(Q_{\text {net }}>0\right.$ and $\left.d Q_{n e t} / d t<0\right)$. The nighttime zone is characterized by a negative net heat flux $\left(Q_{\text {net }}<0\right.$.

In each phase, the maximum increment in $H_{q}$ at the beginning of the nighttime zone (hereafter $\delta H_{q m a x}$ ) is the same for all the models. So is the net increment of $H_{q}\left(\delta H_{q n e t}\right)$ at the end of the diurnal cycle (point D), which is expected since the simulations are all 1D. Both $\delta H_{q m a x}$ and $\delta H_{\text {qnet }}$ are larger in the $\mathrm{R}$ phase compared to the $\mathrm{M}$ phase. A direct comparison of $\delta H_{\text {qmax }}$ and $\delta H_{\text {qnet }}$ from the measured and the modeled water column cannot be done since the vertical resolution in the MLML dataset is coarse.

The maximum increment in the SST over the diurnal cycle (hereafter $\delta S S T_{\max }$ ) and the net SST increment at the end of the diurnal cycle (hereafter $\delta S S T_{n e t}$ ) are both larger in the $\mathrm{R}$ phase compared to the $\mathrm{M}$ phase for all the simulations. Among the models, the KPP shows the largest $\delta S S T_{\max }$ of $0.35^{0} \mathrm{C}$, followed by $\mathrm{CA} 0.28^{0} \mathrm{C}$ and then by PWP $\left(0.23^{0} \mathrm{C}\right)$ during the $\mathrm{R}$ phase. In contrast, the net SST increment $\delta S S T_{\text {net }}$ in the R phase is a maximum $0.08^{0} \mathrm{C}$ for PWP, whereas both CA and $\mathrm{KPP}$ yield $0.04^{0} \mathrm{C}$. The $\mathrm{M}$ phase shows a similar trend where $\delta S S T_{\max }$ is the largest for $\mathrm{KPP}\left(0.09^{0} \mathrm{C}\right)$, and is followed by CA $\left(0.08^{0} \mathrm{C}\right)$ and PWP $0.06^{0} \mathrm{C}$, whereas $\delta S S T_{n e t}$ is the larger for the PWP than CA and KPP. Over multiple diurnal cycles during the two phases, positive $\delta S S T_{n e t}$ from the different simulations increment the SST, thus forming the resultant rise at the end of the spring and fall transitions respectively. We infer from this analysis that KPP yields the largest diurnal amplitude during the morning phase, and is followed by CA and PWP, whereas the net increment of SST at the end of each diurnal cycle is larger for PWP and almost equal for CA and KPP.

Due to larger net heat flux and a weaker wind stress during the R phase, the magnitude of the temperature gradients near the surface are stronger than that in the M phase (Figure 8). The KPP forms stronger positive gradients in temperature compared to CA during the morning and the afternoon zones in each phase, whereas during nighttime zone the temperature gradients from 
Ocean Sci. Discuss., doi:10.5194/os-2016-45, 2016

Manuscript under review for journal Ocean Sci.

both KPP and CA are nearly equal and negative. The formation of these temperature gradients near the surface due to weak eddy diffusivities in CA and KPP, results in a larger excursion of SST in these two simulations compared to the PWP.

During the R phase, the temperature gradients below $10 \mathrm{~m}$ in the PWP simulation show serrated patterns with a larger magnitude of gradients compared to CA and KPP which form relatively smoother profiles (Figure 8f,g,h). These serrated patterns are formed by the end of the $\mathrm{M}$ phase due to alternate mixing and restratification during multiple diurnal cycles as follows: The nighttime cooling in the PWP results in the formation of a sharp temperature gradient at the ML base (Figure 8e). This temperature gradient is stronger in PWP compared to that in CA and KPP. During the subsequent morning phase in the next diurnal cycle, positive net heat flux shallows the mixed layer, inhibiting the turbulent mixing. In the absence of mixing, this sharp temperature gradient formed during the previous diurnal cycle does not diffuse, and remains intact in the water column during the next diurnal cycle (Figure 8c). Over multiple diurnal cycles during the M phase, multiple sharp temperature gradients form, resulting in the serrated patterns noted below $10 \mathrm{~m}$ in the PWP simulation (Figure 8f,g,h). During the R phase, since the MLD is shallow with an average value of $10 \mathrm{~m}$, these serrated patterns remain unaffected by any change in the surface momentum or heat fluxes.

\section{Conclusions}

This paper explores the contrasts between the simulated vertical structure of the upper ocean by three different mixing models: the PWP Bulk mixed-layer model, the KPP non-local model, and the $k-\epsilon$ local mixing model. The PWP also parameterizes the shear instability below the ML and performs convective adjustment for unstable stratification within the ML. The KPP is a widely used non-local mixing model that estimates the depth of the surface boundary layer and parameterizes the eddy diffusivities based on similarity scaling theory. The $k-\epsilon$ is a local mixing model that estimates vertical eddy viscosities (and diffusivities) along the water column based on the local shear and stratification.

For our analysis we choose two different upper ocean datasets, namely the SWAPP and the MLML based on the different dynamics that they represent. Observations during SWAPP show a slab-like velocity distribution within the ML, and strong near-inertial shear over a depth-range from the ML base to the bottom. Observations during MLML show a well-mixed surface boundary layer over the first 22 days, followed by restratification and shallowing of the boundary layer over the next 2.5 months. The SST elevated by $6^{0} \mathrm{C}$ at the end of the restratification phase.

Near the surface, weak eddy viscosity formed by the $k-\epsilon$ and KPP models result in stronger vertical shear in the simulations CA and KPP at all frequencies contained in the wind forcing. This results in the formation of a thin shear layer spanning the sub-inertial and super-inertial frequency range in the rotary auto-spectra. The Bulk mixed-layer model PWP does not form this layer near the surface since the changes in the scalar and momentum properties due to the surface fluxes, are mixed uniformly within the entire ML. Below the ML, all the models form a strong inertial shear. The $k-\epsilon$ model however forms a continuous inertial-shear band whereas the KPP and PWP form discontinuous inertial-shear bands. Apart from the inertial maximum, the models also form a diurnal maximum at the ML base, which arises due to the variation of the shear by the repeated shallowing and deepening of the mixed-layer during the heating and cooling phases of the diurnal cycle. This diurnal maximum is also 
Ocean Sci. Discuss., doi:10.5194/os-2016-45, 2016

Manuscript under review for journal Ocean Sci.

Published: 22 July 2016

(c) Author(s) 2016. CC-BY 3.0 License.

noted within the ML for the $k-\epsilon$ simulation, but not in KPP which is due to the difference between the magnitudes of the eddy viscosities prescribed by the two models. When compared to the observed vertical shear, all the models show a stronger inertial maximum which is due to the absence of internal-wave based mixing present in the observed dataset (Plueddemann and Weller, 1999).

5 Both SWAPP and MLML comparisons show that the PWP evolves a shallower MLD compared to the models $k-\epsilon$ and KPP. At the ML base, the temperature gradient formed by PWP is stronger than those by the models $k-\epsilon$ and KPP. During the M phase of the MLML dataset, continuous deepening and shallowing of the ML result in multiple sharp temperature gradients, thus forming a serrated temperature-gradient profile which is otherwise not present in the $k-\epsilon$ and KPP simulations.

Over a diurnal time-scale, the KPP forms the largest amplitude in the SST over a diurnal cycle, followed by $k-\epsilon$ and PWP. However, the net SST increment over the diurnal cycle is a maximum for the PWP, and is followed by nearly equal increments in $k-\epsilon$ and KPP. This difference between the SST increments from PWP and $k-\epsilon$ or KPP arises due to the formation of strong temperature gradients near the surface in the later, which amplify the SST rise during the daytime heating and further reduce the SST during the nighttime cooling, compared to the absence of gradients formed in the PWP. Over multiple diurnal cycles, the differences between the SST increments accumulate and result in an SST difference of $3^{0} \mathrm{C}$ during the fall transition in the MLML dataset.

Acknowledgements. This work was supported by the Office of Naval Research Grant (N00014-09-1-0196). The 1-dimensional simulations were done with the help of the General Ocean Turbulence Model (GOTM). The authors thank Hans Burchard at the Leibniz Institute for Baltic Sea Research, Sanjiv Ramachandran at the University of Massachusetts Dartmouth, and Albert Plueddemann, Carol Anne Clayson, Thomas Farrar and Robert Weller at the Woods Hole Oceanographic Institution for their valuable inputs. 
Ocean Sci. Discuss., doi:10.5194/os-2016-45, 2016

Manuscript under review for journal Ocean Sci.

Published: 22 July 2016

(c) Author(s) 2016. CC-BY 3.0 License.

\section{References}

Brainerd, K. E. and Gregg, M. C.: Surface mixed and mixing layer depths, Deep Sea Research Part I: Oceanographic Research Papers, 42, 1521-1543, 1995.

Burchard, H.: Applied Turbulence Modeling in Marine Waters, vol. 100 of Lecture Notes in Earth Sciences, Springer, 2002.

5 Burchard, H. and Bolding, K.: Comparative analysis of four second-moment turbulence closure models for the oceanic mixed layer, J. Phys. Oceanogr., 31, 1943-1968, 2001.

Burchard, H., Bolding, K., and Villarreal, M. R.: GOTM - A general ocean turbulence model: Theory, implementation and test cases, Tech. rep., European Commission, 1999.

Canuto, V. M., Howard, A., Cheng, Y., and Dubovikov, M. S.: Ocean turbulence. Part I: One-point closure model—momentum and heat vertical diffusivities, J. Phys. Oceanogr., 31, 1413-1426, 2001a.

Canuto, V. M., Howard, A., Cheng, Y., and Dubovikov, M. S.: Ocean turbulence. Part II: vertical diffusivities of momentum, heat, salt, mass, and passive scalars, J. Phys. Oceanogr., 32, 240-264, $2001 \mathrm{~b}$.

D'Asaro, E.: The energy flux from the wind to near-inertial motions in the surface mixed layer, J. Phys. Oceanogr., 15, 1043-1059, 1985.

Durski, S. M., Glenn, S. M., and Haidvogel, D. B.: Vertical mixing schemes in the coastal ocean: Comparison of the level 2.5 Mellor-Yamada scheme with an enhanced version of the K profile parameterization, J. Geophys. Res., 109, 2004.

Gibson, M. M. and Launder, B. E.: On the calculation of horizontal, turbulent, free shear flows under gravitational influence, Journal of Heat Transfer, 98, 81-87, 1976.

Kantha, L. H. and Clayson, C. A.: An improved mixed layer model for geophysical applications, J. Geophys. Res., 99, 25,235-25,266, 1994.

Kato, H. and Phillips, O. M.: On the penetration of a turbulent layer into stratified fluid, J. Fluid Mech., 37, 643-655, 1969.

Kawai, Y. and Wada, A.: Diurnal sea surface temperature variation and its impact on the atmosphere and ocean: A review, J. Oceanogr., 63, 721-744, 2007.

Kraus, E. B. and Turner, J. S.: A one-dimensional model of the seasonal thermocline II. The general theory and its consequences, Tellus A, $19,1967$.

Large, W. G., McWilliams, J. C., and Doney, S. C.: Oceanic vertical mixing: A review and a model with nonlocal boundary layer parameterisation, Rev. Geophys., 32, 363-404, 1994.

Majumder, S., Tandon, A., Rudnick, D., and Farrar, J.: Near-inertial kinetic energy budget of the mixed layer and shear evolution in the transition layer in the Arabian Sea during the monsoons, J. Geophys. Res., 120, 6492-6507, 2015.

Mellor, G. L. and Yamada, T.: Development of a tubulence closure model for geophysical fluid problems, Reviews of Geophysics and Space Physics, 20, 851-875, 1982.

30 Plueddemann, A. J. and Weller, R. A.: Structure and evolution of the oceanic surface boundary layer during the Surface Waves Processes Program, Journal of Marine Systems, 21, 85-102, 1999.

Pollard, R. T., Rhines, P. B., and Thompson, R. O.: The deepening of the wind-mixed layer, Geophys. \& Astrophys. Fluid Dyn., 4, 381-404, 1972.

Price, J. F.: On the scaling of stress-driven entrainment experiments, J. Fluid Mech., 90, 509-529, 1979.

Price, J. F., Weller, R. A., and Pinkel, R.: Diurnal cycling: Observations and models of the upper ocean response to diurnal heating, cooling and wind mixing, J. Geophys. Res, 91, 8411-8427, 1986.

Rodi, W.: Examples of calculation methods for flow and mixing in stratified flows, J. Geophys. Res., 92, 5305-5328, 1987. 
Ocean Sci. Discuss., doi:10.5194/os-2016-45, 2016

Manuscript under review for journal Ocean Sci.

Published: 22 July 2016

(c) Author(s) 2016. CC-BY 3.0 License.

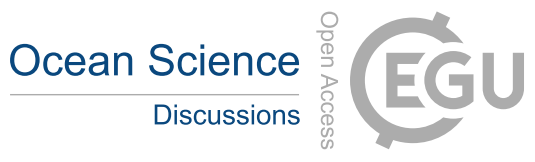

(c) (i)

Stramska, M. and Dickey, T. D.: Vertical structure of the upper ocean during the Marine Light-Mixed Layers experiment, J. Geophys. Res., 100, 6605-6619, 1995.

Troen, I. and Mahrt, L.: A simple model of the atmospheric boundary layer; sensitivity to surface evaporation, Boundary-Layer Meteorology, 37, 129-148, 1986.

5 Umlauf, L. and Burchard, H.: Second-order turbulence closure models for geophysical boundary layers. A review of recent work, Cont. Shelf. Res., 25, 795-827, 2005.

Weller, R. and Plueddemann, A.: Observations of the vertical structure of the oceanic boundary layer, J. Geophys. Res, 101, 8789-8806, 1996.

Willis, G. E. and Deardorff, J. W.: A laboratory model of the unstable planetary boundary layer, Journal of the Atmospheric Sciences, 31, 1297-1307, 1974. 
Ocean Sci. Discuss., doi:10.5194/os-2016-45, 2016

Manuscript under review for journal Ocean Sci.

Published: 22 July 2016

(c) Author(s) 2016. CC-BY 3.0 License.

\section{(c) (1)}

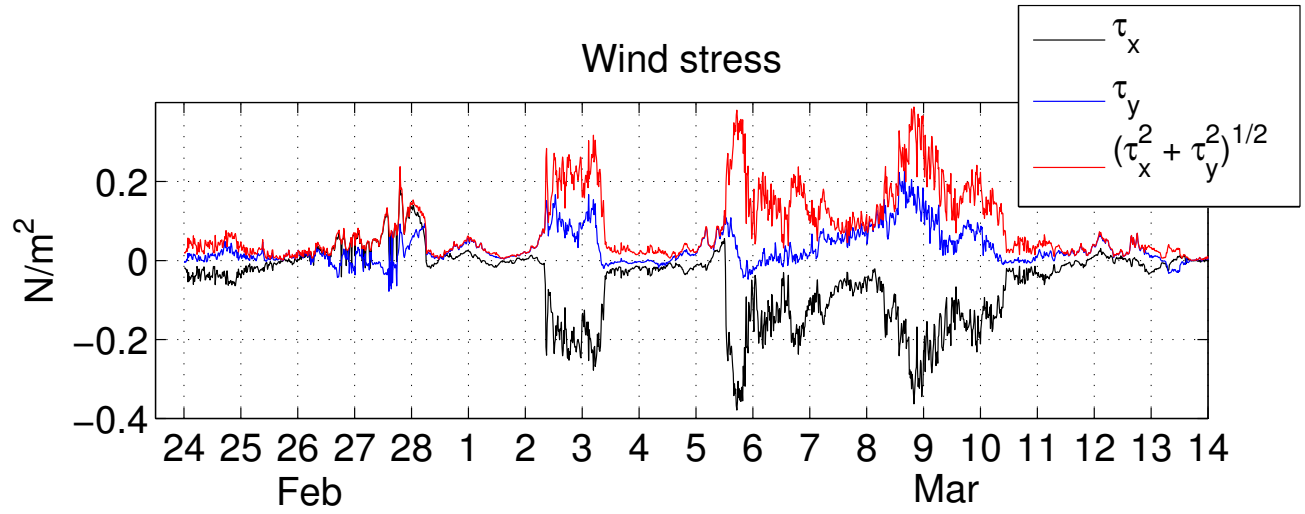

Net heat flux

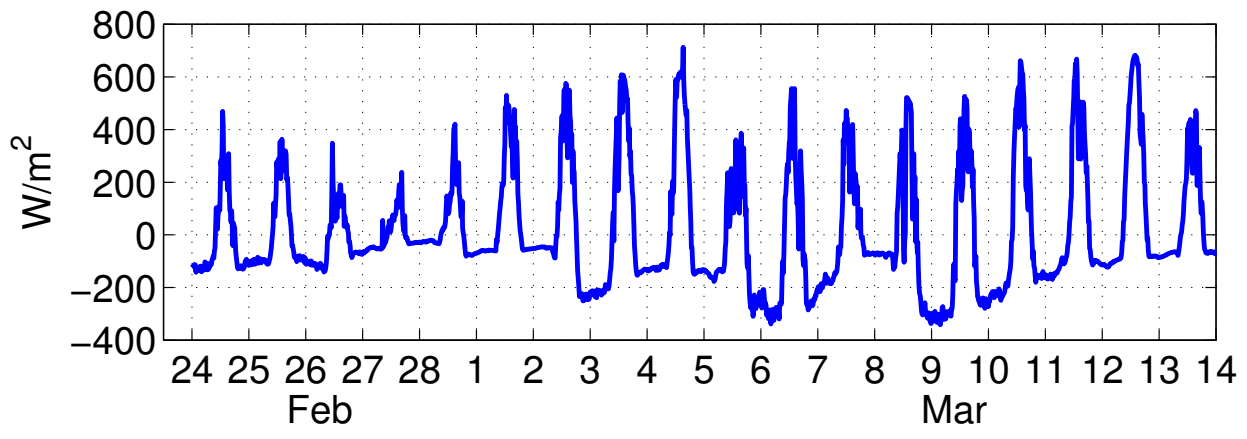

Figure 1. Wind stress and net heat flux observed during SWAPP 
Ocean Sci. Discuss., doi:10.5194/os-2016-45, 2016

Manuscript under review for journal Ocean Sci.

Published: 22 July 2016

(c) Author(s) 2016. CC-BY 3.0 License.
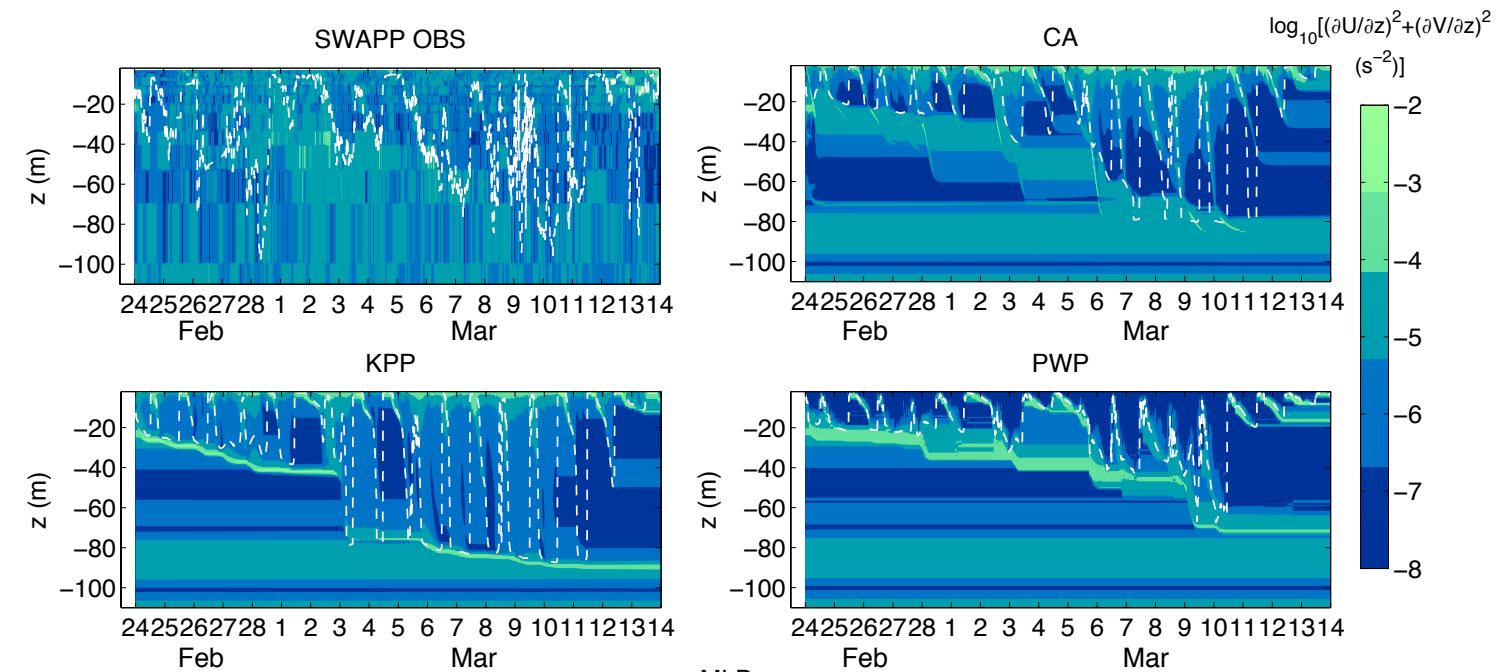

$\left.\left(\mathrm{s}^{-2}\right)\right]$
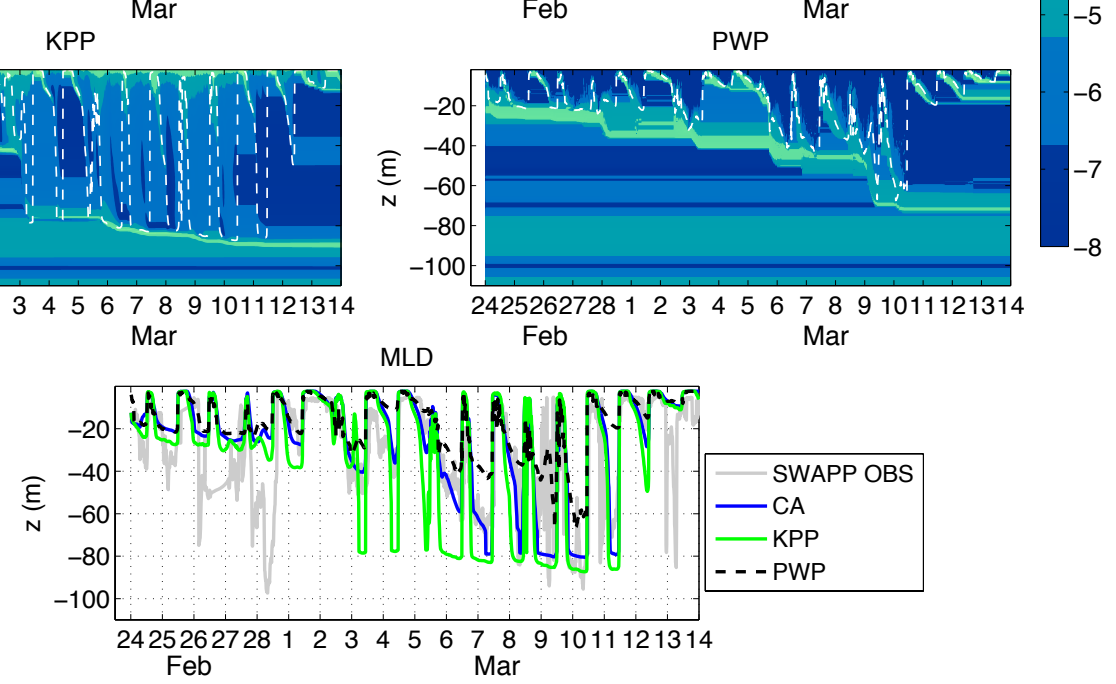

Figure 2. Vertical shear from the observation and model simulations: (a) measurements using VMCM during SWAPP, (b) simulation CA, (c) simulation KPP and (d) simulation PWP. (e) MLD based on a threshold of a temperature difference of $0.01^{\circ} \mathrm{C}$ from the surface. 
Ocean Sci. Discuss., doi:10.5194/os-2016-45, 2016

Manuscript under review for journal Ocean Sci.

Published: 22 July 2016

(C) Author(s) 2016. CC-BY 3.0 License.
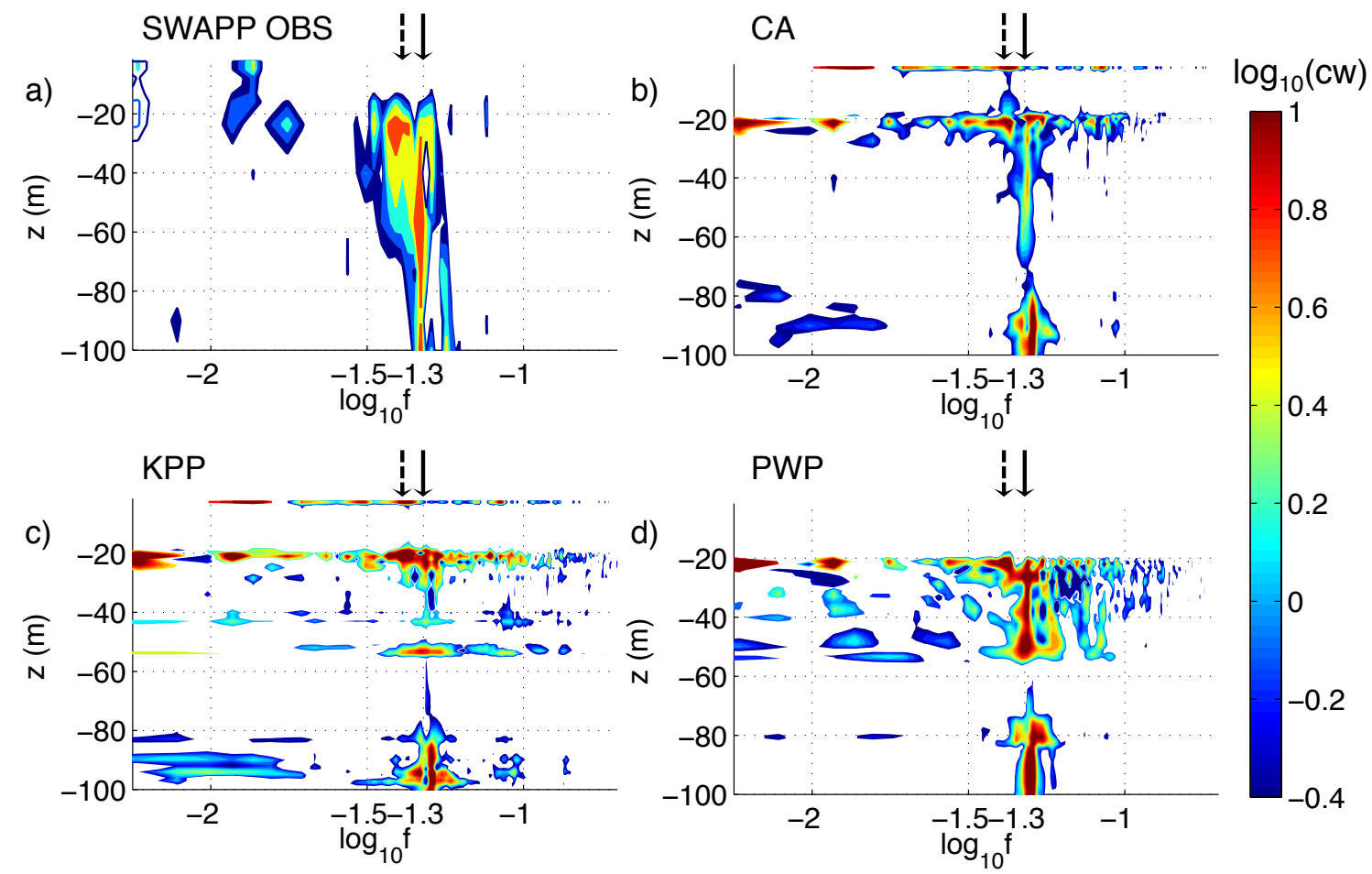

Figure 3. Clockwise component $(\mathrm{cw})$ of the rotary auto-spectra of vertical shear after re-mapping the observed data and the results from simulations CA, KPP and PWP on a vertical grid where the MLD is constant at $20 \mathrm{~m}$. Plot (a) shows the re-mapped shear from observations, (b) simulation CA, (c) simulation KPP and (d) simulation PWP. Plot (a) is a reproduction of the rotary spectral analysis by Plueddemann and Weller (1999). 
Ocean Sci. Discuss., doi:10.5194/os-2016-45, 2016

Manuscript under review for journal Ocean Sci.

Published: 22 July 2016

(c) Author(s) 2016. CC-BY 3.0 License.
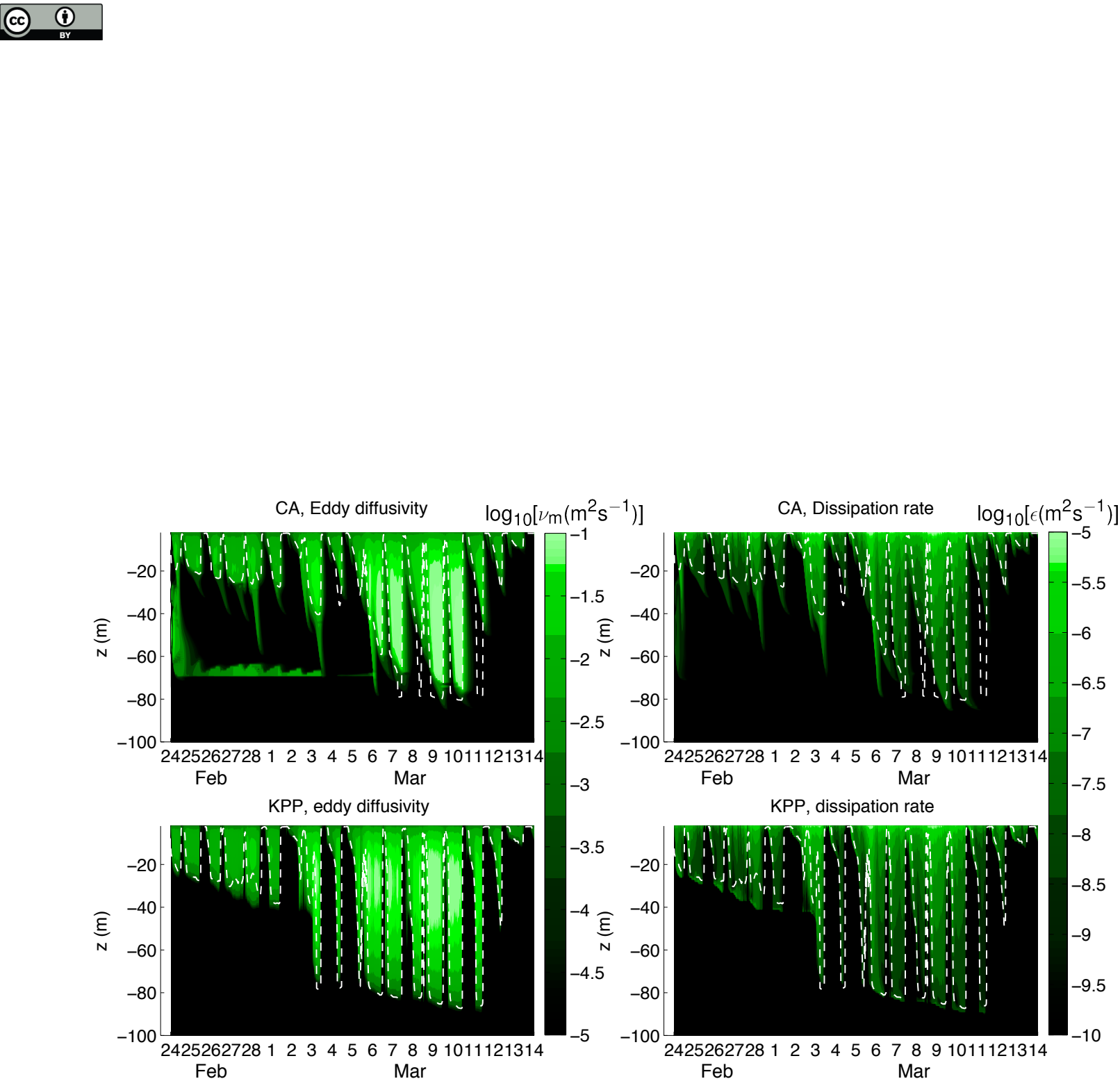

Figure 4. Eddy diffusivities and dissipation rates from simulations CA (plots a and b) and KPP (plots c and d). 
Ocean Sci. Discuss., doi:10.5194/os-2016-45, 2016

Manuscript under review for journal Ocean Sci.

Published: 22 July 2016

(C) Author(s) 2016. CC-BY 3.0 License.
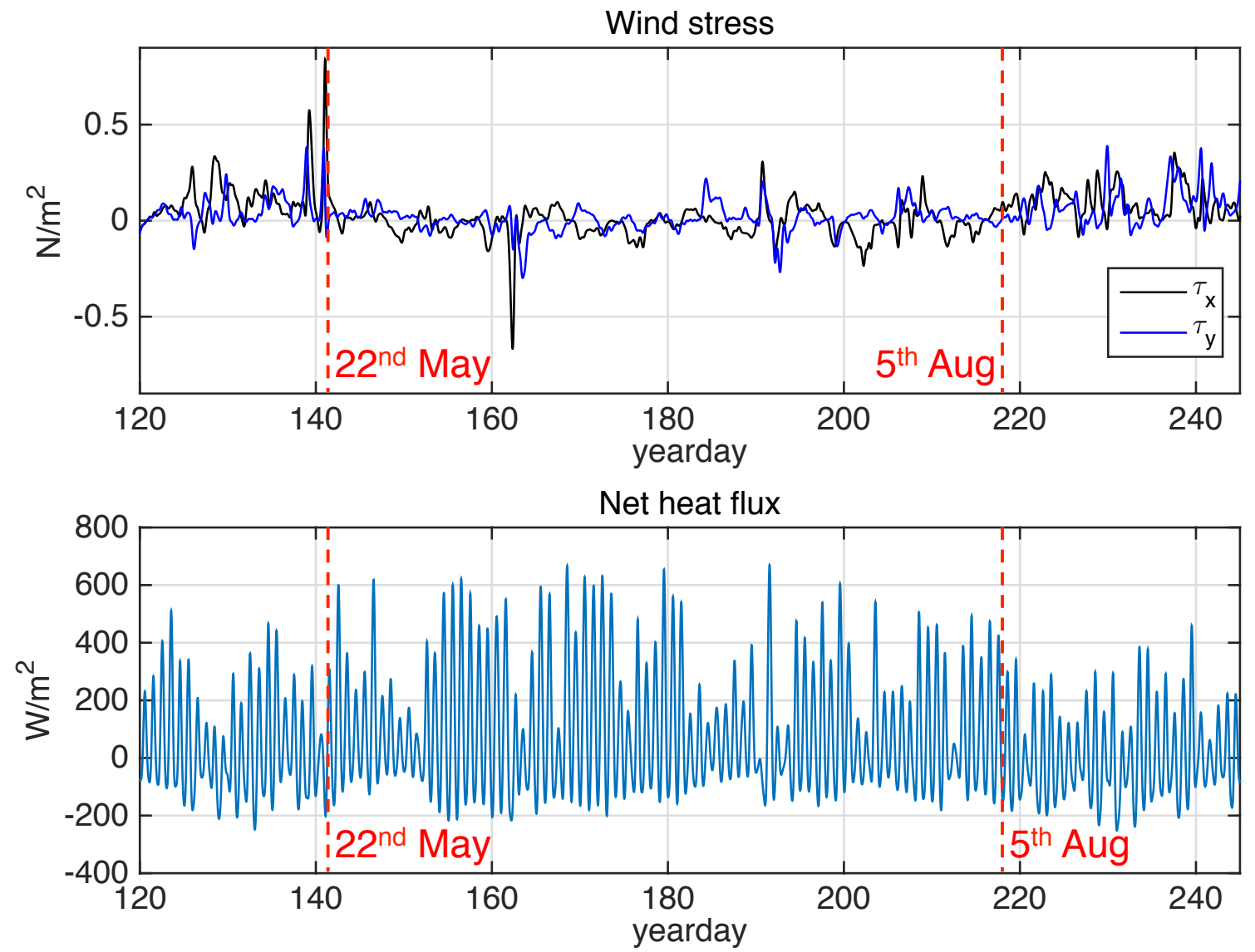

Figure 5. Atmospheric forcing from the MLML observations. The top plot shows the zonal $\left(\tau_{x}\right)$ and meridional $\left(\tau_{y}\right)$ wind stress. The bottom plot shows the net surface heat flux which is a combination of the shortwave radiation, longwave radiation, latent heat and sensible heat loss. The fluxes shown in these plots are lowpassed to filter the values corresponding to all the frequencies higher than $1 / 12 \mathrm{cycles} / \mathrm{hr}$ for clarity. The mixing phase ends on 22nd May (red dashed line) and the restratification phase ends on 5th August (red dashed line). 
Ocean Sci. Discuss., doi:10.5194/os-2016-45, 2016

Manuscript under review for journal Ocean Sci.

Published: 22 July 2016

(c) Author(s) 2016. CC-BY 3.0 License.
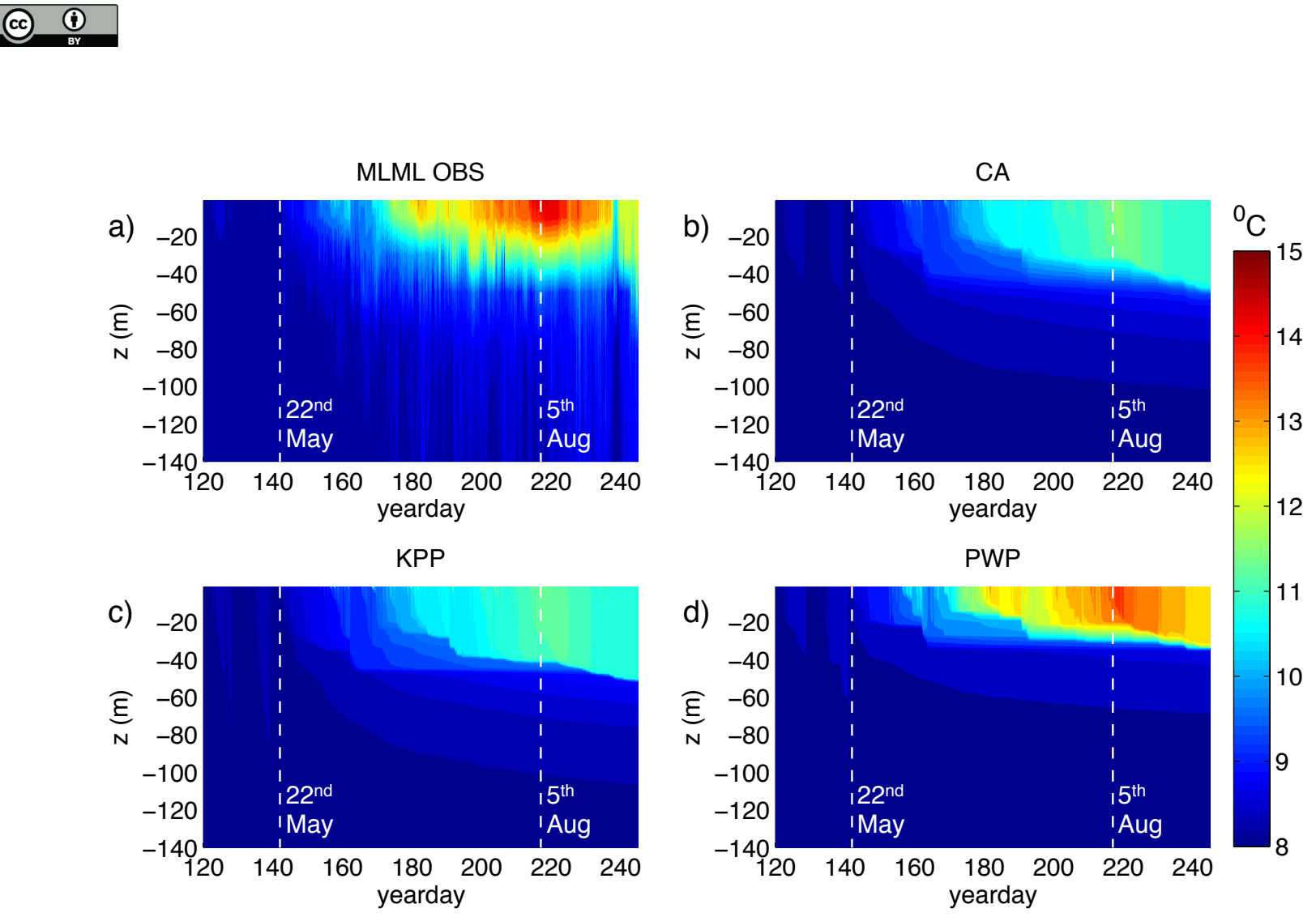

Figure 6. Time evolution of the temperature profiles from (a) observations, (b) simulation CA, (c) simulation KPP, and (d) simulation PWP. The Spring and Fall transitions (22nd May and 5th August respectively) are marked as dashed white lines.

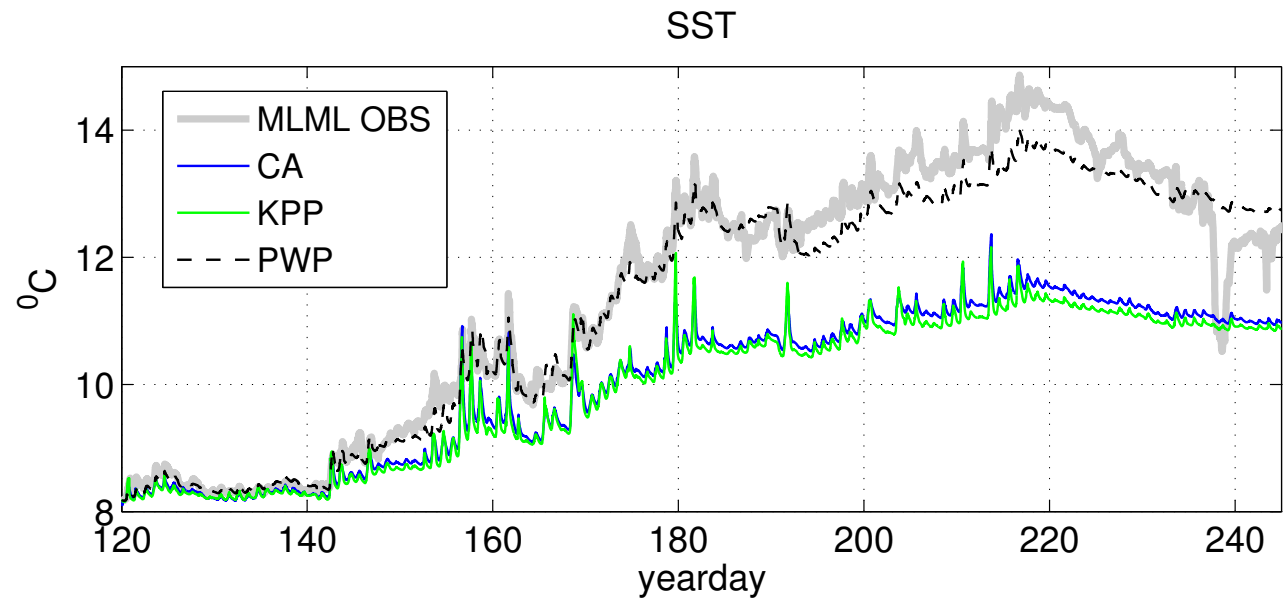

Figure 7. Time series of the SST from observations and model results. 
Ocean Sci. Discuss., doi:10.5194/os-2016-45, 2016

Manuscript under review for journal Ocean Sci.

Published: 22 July 2016

(c) Author(s) 2016. CC-BY 3.0 License.

Mixing phase

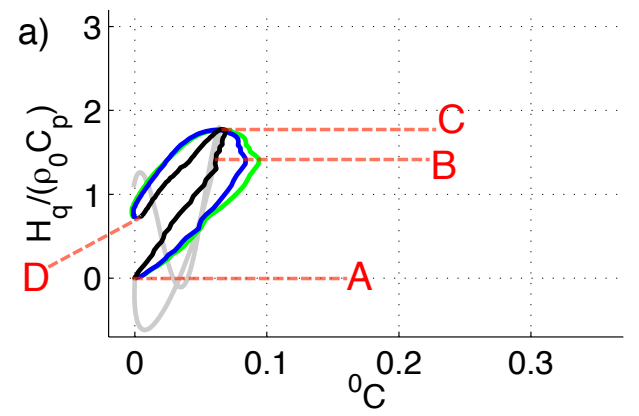

Restratification phase

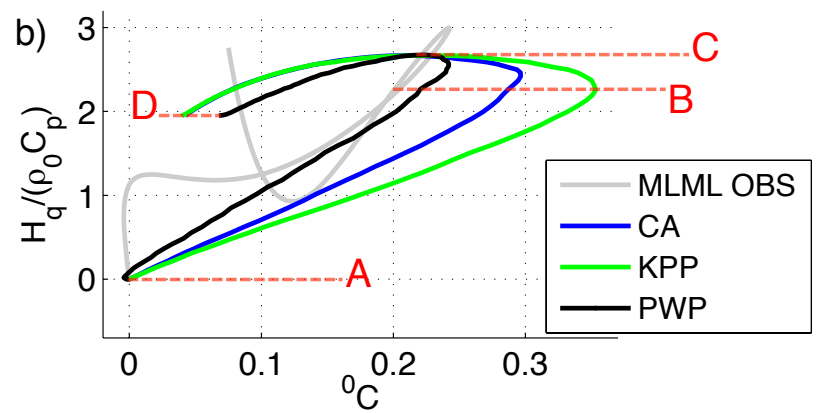

$M$ phase: $A->B$

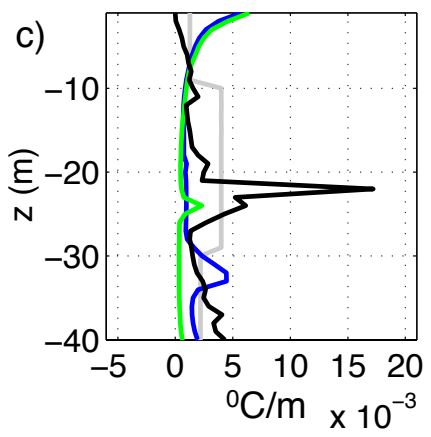

$R$ phase: $A \rightarrow B$

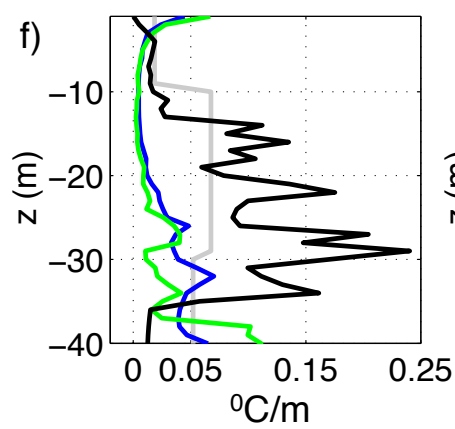

M phase: $\mathrm{B}->\mathrm{C}$

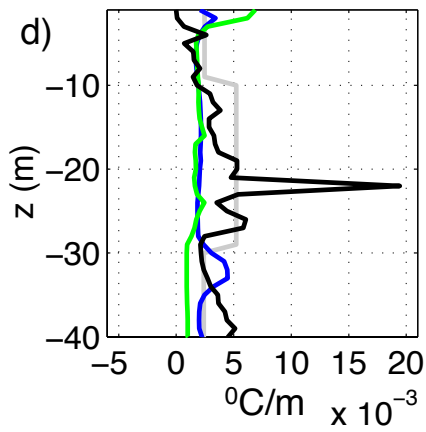

$R$ phase: $B \rightarrow C$

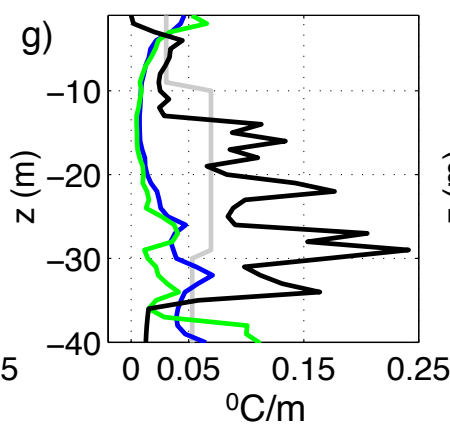

M phase: $C \rightarrow D$

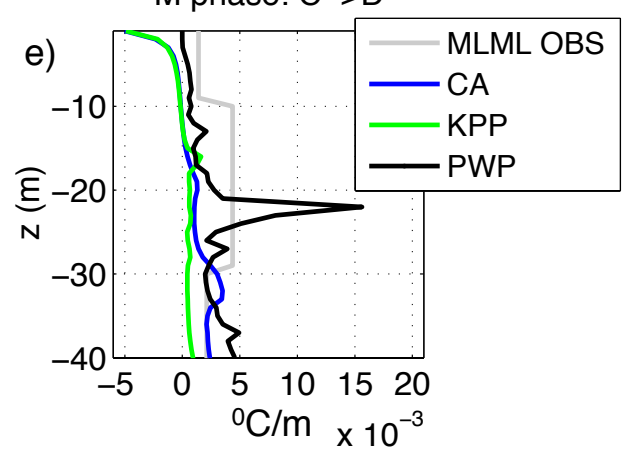

R phase: $C \rightarrow D$

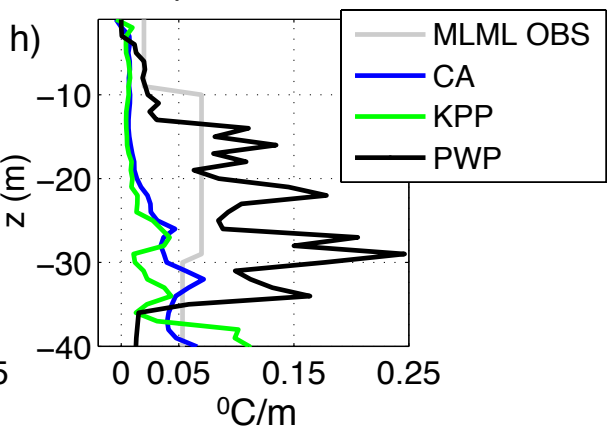

Figure 8. Hysteresis showing the variability of SST with the heat content during the M and R phases of the MLML dataset, averaged over the diurnal cycles during the 2 phases. Plot (a) shows the hysteresis during the $\mathrm{M}$ phase, and plot (b) shows the hysteresis during the R phase. Both plots show the morning zone $(\mathrm{A} \rightarrow \mathrm{B})$, the afternoon zone $(\mathrm{B} \rightarrow \mathrm{C})$ and the nighttime zone $(\mathrm{C} \rightarrow \mathrm{D})$. Plots $(\mathrm{c})$, $(\mathrm{d})$ and $(\mathrm{e})$ show the temperature gradients averaged over each of the zones during the M phase. Plots (f), (g) and (h) show temperature gradients averaged over each of the zones during the $\mathrm{R}$ phase. 
Ocean Sci. Discuss., doi:10.5194/os-2016-45, 2016

Manuscript under review for journal Ocean Sci.

Published: 22 July 2016

(c) Author(s) 2016. CC-BY 3.0 License.

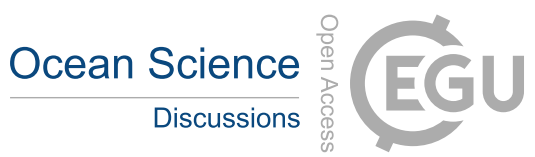

(c)

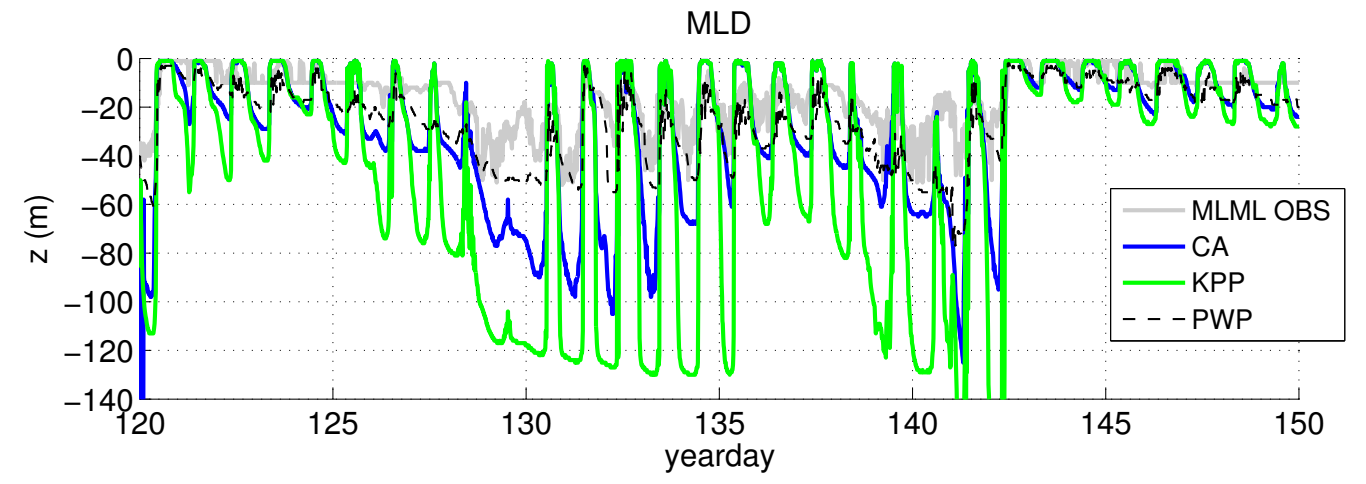

Figure 9. MLD from the observation and model simulations. 